\title{
Global Access Programs: A Collaborative Approach for Effective Implementation and Management
}

\author{
Debra Ainge $^{1} \cdot$ Suzanne Aitken $^{1} \cdot$ Mark Corbett $^{1} \cdot$ David De-Keyzer $^{1}$
}

Published online: 26 March 2015

(c) The Author(s) 2015. This article is published with open access at Springerlink.com

\begin{abstract}
Global access programs (GAPs) provide access to medicinal products for patients with serious medical conditions and no commercially available treatment options. Providing early access to medicines can be challenging for a pharmaceutical company. The demand for a GAP often occurs at a time when other activities are the prime focus, such as delivery of pivotal clinical trials or gaining of marketing authorization. Furthermore, the skills, experience, and infrastructure necessary to implement and manage a successful GAP vary significantly from those required for regular clinical trial execution, and the regulatory environment presents its own challenges, with regulations often poorly defined and with considerable inter-country variation. This article considers the triggers for early access requests and examines the need for companies to develop a global strategy for GAPs in order to respond appropriately to requests for early access. It also provides a comprehensive overview of the processes for GAP set-up, implementation, management, and closure, along with the considerations affecting the type and scope of GAP, such as demand, regulatory feasibility, license status of the product, drug pricing structure, company strategy, costs, and product supply. Also discussed is the need for appropriate personnel to implement and manage the GAP, and when to consider collaboration with an external GAP provider. In summary, GAPs require careful and efficient planning and management, from set-up to closure. Wellrun GAPs provide an ethical and regulatory-compliant
\end{abstract}

Suzanne Aitken

Suzanne.Aitken@clinigengroup.com

1 Clinigen Healthcare Limited, Pitcairn House, Crown Square, Centrum 100, Burton-on-Trent, Staffordshire DE14 2WW, UK pathway for access of new treatments to patients with serious conditions and an unmet medical need.

\section{Key Points}

In order to be able to respond to requests for early access of a drug in a timely manner, companies should plan to implement a comprehensive strategy at a global level.

The type and scope of the global access program (GAP) that is run will depend on considerations such as demand, regulatory feasibility, the license status of the product, and necessary drug pricing structure, as well as company strategy, costs, and product supply.

Successful GAPs require careful and efficient planning and management, from set-up to closure, by either an internal coordinating project manager or a specialist provider.

Throughout the article, we use the term 'GAP'. These are often referred to as early access programs, but we use this as an umbrella term that covers multiple scenarios including, but not limited to, where the medicinal product may be completely unlicensed globally but also where it may be approved in a major market but is not yet approved in the country of required supply.

\section{Introduction}

When patients with a serious medical condition have exhausted all available treatment options and enrollment into a clinical trial is not a possibility, patients and their 
physicians may consider accessing promising new and commercially unavailable treatments via a 'global access program' (GAP), on either a single patient or cohort-based level.

GAPs allow access to medicinal products that are not commercially available in a patient's country, e.g., if a product is in clinical development, is licensed in a country other than the patient's own, is licensed but not commercially available, or has been withdrawn.

The demand for GAPs from patients and their carers is increasing, with high-profile cases in the press and social media gaining much attention. This trend is likely to continue as pharmaceutical and biotechnology companies continue to focus on developing medicines in areas of high unmet need and as patients and healthcare professionals monitor product pipelines and developments more closely.

Providing access to medicines that are not commercially available in a patient's country can be challenging for pharmaceutical and biotechnology companies, with confusion and misconceptions about what is and what is not possible. GAPs differ fundamentally from clinical trials and some of the differences have been summarized in a recent publication [1]. The primary focus of a clinical trial is demonstration of safety and efficacy, whereas a GAP is focused upon meeting an unmet patient need. Given the differences between the two, it is not surprising that the skills, experience, and infrastructure necessary to implement and manage a successful GAP vary significantly from those required for clinical trial execution.

Furthermore, the regulatory environment presents its own challenges, as unlicensed use outside of clinical trials is governed by different regulations to those covering clinical trial set-up and delivery (with the exception of regulations in the USA [2, 3]); regulations are also often poorly defined, open to interpretation, and vary considerably from country to country outside of the USA. As a result, companies that have limited experience and practical knowledge of GAPs can find it difficult to navigate this complex area.

This article focuses on GAPs run outside of the USA, although many aspects are equally applicable to the USA. It examines the triggers for early access requests, how such requests can be responded to, regulatory considerations, and the processes for set-up, implementation, management, and closure of GAPs.

\section{Triggers for Early Access Requests}

The main trigger for a pharmaceutical or biotechnology company (the sponsor) to consider implementing a GAP is the receipt of requests from patients or their physicians. Requests are often triggered by events or conferences announcing promising results from clinical trials. They may also occur when a product receives approval in another country, when patients exiting clinical trials wish to continue on treatment, or when investigators have patients that do not meet the eligibility criteria for a trial but still may benefit from treatment. Requests for early access generally occur when there is some evidence of safety and efficacy from phase II/III trials. However, dependent on the severity of the unmet need, it can be earlier than this, as demonstrated recently when patients infected with the Ebola virus were the first human subjects to receive the experimental ZMapp treatment [4].

\section{Response to Early Access Requests: Development of Company Guidance}

A pharmaceutical company should produce a comprehensive, product-specific, country-by-country plan for a GAP, to implement, manage, and exit the program in each country. Several previous articles have proposed decision trees and go/no-go decisions for whether a company should initiate a GAP [5, 6]. Here, we examine the key elements that a pharmaceutical company will need to consider in order to be able to plan and respond appropriately and efficiently to requests for early access. Regulatory considerations are covered separately in Sect. 4 below.

In order to be able to respond to such requests in a timely manner, companies should plan to implement a comprehensive strategy at a global level. This is particularly relevant for companies involved in the development of products in areas of high unmet need, where there is an absence of approved and commercially available alternative treatments on the market. A company guidance document or standard operating procedure should include details of when programs need to be considered (phase in development, therapy area, patient population), who will be the decision makers and governance bodies, how and by whom a program should be implemented, how often individual project strategies should be reviewed, and budgetary considerations. One option is for the global project development team to include an access program review at project milestones, such as when a product enters development, and at each clinical milestone thereafter. The guidance document should provide clear direction for project teams and be flexible enough to allow adaption for each particular product and request scenario. Key aspects to be considered when developing company guidance are detailed below.
(a) Assignment of global access program (GAP) team roles and responsibilities
The key decision makers and their roles should be 
Table 1 Roles of sponsor personnel in global access program planning

\begin{tabular}{|c|c|}
\hline Key sponsor personnel & Role \\
\hline Senior management teams & $\begin{array}{l}\text { Key decision makers regarding the strategy for the implementation of GAPs, particularly concerned with } \\
\text { the impact on the company and its reputation }\end{array}$ \\
\hline Procurement/global external sourcing & $\begin{array}{l}\text { May have significant involvement in GAP partner selection, with a focus on cost and on compliance } \\
\text { with internal procurement procedures }\end{array}$ \\
\hline Clinical development team & Key decision makers in the initiation of GAPs. Some of their main objectives are to: \\
\hline $\begin{array}{l}\text { Clinical operations team } \\
\text { Medical directors }\end{array}$ & $\begin{array}{l}\text { Ensure the establishment of an effective and efficient GAP process (with consideration of the potential } \\
\text { impact of a GAP on parallel clinical trial recruitment) }\end{array}$ \\
\hline Therapy area specialists & $\begin{array}{l}\text { Define the process for patient screening and the criteria for eligibility } \\
\text { Implement the necessary training, e.g., for affiliates and prescribers, and plan communications such as } \\
\text { press releases }\end{array}$ \\
\hline Regulatory affairs managers & $\begin{array}{l}\text { Decision makers in GAP design and planning, concerned with compliance with individual country } \\
\text { regulatory requirements and the potential impact of an access program on other regulatory activities } \\
\text { such as marketing authorization applications (EU) or new drug applications (USA) }\end{array}$ \\
\hline Market access and brand managers & $\begin{array}{l}\text { Keen interest in the potential return on investment from running a GAP, and the potential impact on } \\
\text { product launch plans and commercialization, as well as on product price and reimbursement }\end{array}$ \\
\hline Pharmacovigilance & $\begin{array}{l}\text { Consulted regarding plans for patient follow-up and adverse event collection, and will have an ongoing } \\
\text { involvement in the reporting of safety events during the program }\end{array}$ \\
\hline Quality compliance personnel & $\begin{array}{l}\text { May be involved in a number of aspects of the GAP such as pre-selection of supplier to ensure } \\
\text { compliance with company standards, integration of the GAP process into company standard operating } \\
\text { procedures, product labeling and release, recall procedures, validation of shipping routes and } \\
\text { packaging, facilities and licenses, and data protection }\end{array}$ \\
\hline $\begin{array}{l}\text { Chemistry manufacturing controls } \\
\text { and supply chain }\end{array}$ & $\begin{array}{l}\text { Consulted for information around the availability of the product, labeling and qualified person } \\
\text { requirements, and changes in product presentation throughout the program }\end{array}$ \\
\hline
\end{tabular}

$G A P$ global access program

identified and the contributions of individual functions, project teams and stakeholders should be considered. A typical list of those who may need to be involved is included in Table 1, along with their anticipated roles in the program.

There will be significant differences in the way that companies manage GAPs, depending on their size and organizational structure. Small to mid-size companies, compared with large pharmaceutical companies, tend to have simpler governance and decision-making processes but less in-house experience and resources for managing a GAP.

Companies with large geographical footprints will need to consider the role of local affiliates/operating companies during both the set-up and delivery phases. These groups may often have strong opinions regarding the activities in their countries; this can potentially lead to a lack of a coherent global strategy and inconsistent implementation. On the other hand, the support of local affiliates may be necessary or advantageous, e.g., the use of affiliate pharmacovigilance services. Hence, early engagement is recommended to ensure that the global strategy is adopted within the regulations of the particular country, and that the appropriate level of involvement of an affiliate is incorporated into the program.

Given the number of decision makers, specialists, and stakeholders involved, it is strongly recommended that a project manager is appointed, who can undertake a central role in coordinating and managing team input. The project manager needs to ensure that the program is designed, set up, and managed to meet the objectives of the GAP, as well as managing any inter-dependencies with other product activities, such as ongoing clinical trials or marketing authorizations. They should also ensure adequate and ongoing stakeholder management throughout the project.

(b) Consideration of collaboration with external GAP specialist providers

Another key consideration is the organization's knowledge of GAPs, and when it may be beneficial to bring in outside expertise with practical experience, not only in the context of development of the strategy and implementation of programs, but also to assist with training and communication within the organization, and ongoing management of the program. While some companies choose to upskill a project 
manager internally to act as a central point of knowledge regarding GAPs, others may choose to use external specialist providers to provide the detailed knowledge and support the organization's internal teams through design and delivery.

(c) Definition of strategy for internal and external communication

Communication is vital to the success of a GAP in delivering its objectives and should be a key element defined in the corporate guidance.

Internal communication is important to ensure stakeholder buy-in, awareness of GAP launches and milestones, and education of any personnel likely to be involved in a program and/or potentially receiving requests for medication. Corporate guidance should define the timeliness and content of training of project, development, and commercial teams.

External communication of GAPs is a difficult area and one where there is often much debate within organizations around what is acceptable from a regulatory viewpoint. It is important that corporate guidance defines how the GAP will be communicated externally, to ensure both regulatory compliance and upfront agreement with internal stakeholders as to acceptable communications. Particularly in the areas of rare diseases and orphan drugs, there is also an opportunity to work with patient advocacy groups and organizations to ensure information is widely available through them.

(d) Assessment of pharmaceutical supply of the drug A key element for consideration is the quantity of the drug available. Whether the drug is clinical trial material or a licensed pack from a territory with a marketing authorization will impact both the geographical scope and regulatory assessment. It is important to ensure that there is sufficient inventory (or plans to replenish) in order to supply requests, particularly for long-term treatments. Where there is a limited inventory, it may be necessary to restrict access either on a first-come-first-served basis or, for example, on a patient-screening basis, to ensure that those who are assessed to benefit most receive the available medication. Any re-supplies for ongoing and long-term treatment needs to be factored in to this planning. Adequate supply-chain planning is one area that is frequently overlooked in GAP feasibility assessment.

(e) Planning of exit strategy

Another important consideration that may influence the project scope is the exit strategy. Depending on the type and duration of treatment and launch plans for the product, this strategy will vary considerably between programs and should be factored into planning at an early stage. The situation in the EU for products licensed via the centralized procedure is particularly complex, with product approval and subsequent launch often occurring many months apart [7]. This should be factored in from the outset, coupled with consideration that some regulatory mechanisms stipulate that a product provided within the context of a GAP should be made available to the patient until the product is commercially available and reimbursed within the patient's country, or provided free of charge for the duration of the patient's treatment. Since the exit strategy will potentially be communicated to prescribers, health authorities, and other interested parties at the outset, it is difficult to change this position once stated, so upfront planning for closure is vital in the planning phase.

(f) Consideration of pricing strategy

Another key consideration for the organization is whether they wish to provide the product free of charge or if they wish to charge for access. This will impact on the possible regulatory routes available and, if the sponsor wishes to charge for access, may limit the territory scope feasible (see Table 2). Sponsors are often concerned about setting an appropriate price for access through GAPs and care should be taken to ensure that this does not compromise subsequent pricing and reimbursement negotiations. For this reason, a premium on the first planned launch price is typically recommended.

(g) Assessment of data collection requirements

Whilst collection of efficacy data should not be the drive of a GAP, some data may be collected through the delivery of a GAP which reflects real-world data regarding the use of the product outside of the confines of a clinical trial. Consideration of what information can be gathered during a GAP should be made at the outset and may include, but not be limited to, patient demographics, physician and institute information, patient screening and eligibility, intended use, and follow-up/outcome data.

\section{Regulatory Considerations}

Health authorities around the world have recognized the need to allow treatment with an unlicensed product for patients suffering from serious or life-threatening conditions where licensed alternatives are either unavailable or unsuitable for the patient. In the EU, European Medicines Agency guidelines and directives [8-10] provide the regulatory framework for access to unlicensed medicines 
Table 2 Factors affecting decision on global access program type

\begin{tabular}{|c|c|c|}
\hline \multirow[t]{2}{*}{ Factors to consider } & \multicolumn{2}{|l|}{ Global access program type } \\
\hline & Single-patient access & Cohort access \\
\hline Pricing structure & $\begin{array}{l}\text { Majority of countries allow charging for product, with } \\
\text { exceptions in the case of some investigational medical } \\
\text { products }\end{array}$ & $\begin{array}{l}\text { Majority of cohort approaches mandate free-of-charge } \\
\text { product, with a commitment to ensuring supply until } \\
\text { product is commercially available in a patient's } \\
\text { country }\end{array}$ \\
\hline Pharmacovigilance & $\begin{array}{l}\text { Generally limited to spontaneous reporting by the } \\
\text { physician directly to the competent health authority }\end{array}$ & $\begin{array}{l}\text { Often a requirement for monitoring or additional } \\
\text { reporting by sponsor company }\end{array}$ \\
\hline $\begin{array}{l}\text { Product availability and } \\
\text { labeling }\end{array}$ & $\begin{array}{l}\text { English pack, labeled in accordance with guidance note } \\
14 \text { [15], is generally acceptable for an investigational } \\
\text { medicinal product. In the case that the product is } \\
\text { approved in another country, the licensed pack from } \\
\text { that country can be used }\end{array}$ & $\begin{array}{l}\text { Often a requirement for a specifically labeled pack, in } \\
\text { local language }\end{array}$ \\
\hline Set-up time and costs & $\begin{array}{l}\text { Generally, a program-wide approach can be } \\
\text { implemented across all countries, limiting the time } \\
\text { and resources needed }\end{array}$ & $\begin{array}{l}\text { Additional time and resources to prepare country- } \\
\text { specific protocols, informed consent forms and } \\
\text { supporting information, and for subsequent } \\
\text { submission and approval }\end{array}$ \\
\hline
\end{tabular}

Table 3 Overview of single-patient and cohort access programs

\begin{tabular}{|c|c|}
\hline Single-patient access & Cohort access \\
\hline $\begin{array}{l}\text { Provision of controlled, pre- } \\
\text { approval access to a drug } \\
\text { before it is licensed and } \\
\text { commercially available in the } \\
\text { patient's home country }\end{array}$ & $\begin{array}{l}\text { Provision of controlled, pre- } \\
\text { approval access to a drug } \\
\text { before it is licensed and } \\
\text { commercially available in the } \\
\text { patient's home country }\end{array}$ \\
\hline $\begin{array}{l}\text { A specific regulatory process is } \\
\text { defined in each country for } \\
\text { approval of access for a single } \\
\text { patient }\end{array}$ & $\begin{array}{l}\text { A specific regulatory process is } \\
\text { defined in each country for } \\
\text { approval of access for cohorts } \\
\text { of patients }\end{array}$ \\
\hline $\begin{array}{l}\text { Individual access is initiated by a } \\
\text { patient's physician }\end{array}$ & $\begin{array}{l}\text { A program is defined for access } \\
\text { for a group of patients, initiated } \\
\text { by pharmaceutical company or } \\
\text { their representative }\end{array}$ \\
\hline $\begin{array}{l}\text { Generally short approval } \\
\text { timelines }\end{array}$ & Approval times can be lengthy \\
\hline
\end{tabular}

outside the context of the clinical trial. Although this EU framework exists, each member state has defined independently how and when to allow such access, and have developed national rules and legislation to reflect this [1114]. As a result, regulations vary considerably from country to country, with more than 100 different regulations across the member states $[5,12,13]$. This is further compounded for products that undergo centralized market authorizations, which results in a product being simultaneously approved in each member state, but commercially unavailable in every country until the additional countryspecific requirements for labeling, pricing, reimbursement, and launch are completed, further delaying patient access to potentially life-saving treatments [7].

Given the complexity of the regulations, the regulatory environment for the specific product should be assessed during the initial planning phase for a GAP, and should consider the following factors:

- license status of the product (completely unlicensed, licensed in the country in question but not commercially available, not licensed in the country in question but licensed in another country, withdrawn); and

- patient population (ex-clinical trial patients, new patients, patients not meeting eligibly criteria of ongoing trials).

Assessment of the regulatory environment for a product will, for example, identify countries where supply is not possible or instances where more than one potential route for access exists, requiring a choice between a single-patient or cohort approach (Table 3). In these instances, the sponsor may often have a preference on the regulatory route to use, depending on other factors such as pricing structure, pharmacovigilance capabilities in the country, product availability, and labeling and set-up times and costs (Table 2).

Other factors that may influence the feasibility in a particular European country include product type (small molecule, biological, blood product, etc.), country of manufacture, licensed indication, and country of authorization (if applicable).

In contrast to the EU, US regulations for unlicensed use are described under US clinical trial legislation [2,3]. As a result, there is more overlap with traditional clinical trial processes than elsewhere in the world, such as requirements for monitoring, safety data collection, reporting, and site management, which places significant burden upon both the pharmaceutical company and physician, and is believed to be an important factor in explaining why the numbers of patients accessing unlicensed medicines in the USA is still relatively low $[16,17]$. 
Regulations across countries outside of the EU and USA can vary widely and may often be ill-defined, particularly in countries with limited pharmaceutical markets. In general, only a few such countries permit a cohort approach, whereas most of these countries allow single-patient access routes. Single-patient access in these countries often relies

Table 4 Set up and implementation activities

\begin{tabular}{|c|c|}
\hline Area & Set up and implementation activities \\
\hline $\begin{array}{l}\text { Process and } \\
\text { documentation }\end{array}$ & $\begin{array}{l}\text { Preparation of information to be provided to } \\
\text { healthcare professionals relating to the GAP } \\
\text { and the product } \\
\text { Definition of patient population, eligibility } \\
\text { criteria, medical review processes, and how } \\
\text { these will be managed } \\
\text { Arrangement of compliant management } \\
\text { process for patient data and reporting, and } \\
\text { medical information enquiries }\end{array}$ \\
\hline Quality and safety & $\begin{array}{l}\text { Management of product presentation, labeling, } \\
\text { and qualified person certification and release } \\
\text { (if applicable) } \\
\text { Adherence to company standard operating } \\
\text { procedures } \\
\text { Definition of process for managing } \\
\text { pharmacovigilance }\end{array}$ \\
\hline Regulatory & $\begin{array}{l}\text { Communication with agencies, and preparation } \\
\text { of protocols, submissions, and timelines } \\
\text { Management of request for regulatory support } \\
\text { from healthcare professionals } \\
\text { Ongoing agency communication throughout } \\
\text { the program at product milestones }\end{array}$ \\
\hline $\begin{array}{l}\text { Supply chain and } \\
\text { logistics }\end{array}$ & $\begin{array}{l}\text { Preparation of a logistics plan to consider } \\
\text { courier selection, in-country representation, } \\
\text { shipment conditions and frequency, and } \\
\text { import requirements of the product } \\
\text { Management of small, frequent, direct-to-site } \\
\text { shipments in appropriate turnaround times } \\
\text { Planning for any restrictions in stock } \\
\text { availability, and potential application of a } \\
\text { patient number cap }\end{array}$ \\
\hline $\begin{array}{l}\text { Commercial and } \\
\text { financial }\end{array}$ & $\begin{array}{l}\text { Decision on price to be charged for product } \\
\text { Consideration of impact of project milestones } \\
\text { on pricing and any requirement for 'switches' } \\
\text { (e.g., products may initially be provided free } \\
\text { of charge until approved in a major market, } \\
\text { and then be transitioned to 'paid for'), as well } \\
\text { as assessment of pricing impact on final } \\
\text { commercial price } \\
\text { Ongoing budget monitoring and control }\end{array}$ \\
\hline $\begin{array}{l}\text { Communication } \\
\text { and training }\end{array}$ & $\begin{array}{l}\text { Agreement on required communication and } \\
\text { training, including press releases, } \\
\text { conferences, and electronic media } \\
\text { Engagement with patient advocacy groups and } \\
\text { organizations } \\
\text { Management of communication with sponsor } \\
\text { stakeholders }\end{array}$ \\
\hline
\end{tabular}

GAP global access program on personal importation by the patient or patient's family, or is limited to products that are already approved in a major pharmaceutical market such as the USA, Japan, or the EU.

\section{Set-Up and Implementation of a GAP}

Set-up and implementation activities fall into defined areas and require specialist input, with centralized management of the various functions involved. Some of the activities that need to be considered are shown in Table 4 .

\section{Ongoing Management and Program Closure}

Once the GAP is launched, ongoing management is required to ensure successful delivery. This will include monitoring of stock levels, resolution of any issues, and, in particular, management through key lifecycle milestones such as approvals in the USA or EU, commercialization in each country, extension to new countries, variations to drug product used, changes in pricing strategy, and, of course, the program exit strategy at its conclusion.

\section{Conclusions}

The initiation and management of a GAP can be challenging and requires careful assessment and planning. The demand for a program often occurs at the very time companies are focused on other activities such as the delivery of pivotal clinical trials or gaining of marketing authorization.

In order to be able to respond to requests for early access in a timely manner, companies should plan to implement a comprehensive strategy at a global level. This is particularly relevant for companies involved in the development of products in areas of high unmet need, where there is an absence of approved and commercially available alternative treatments on the market.

The type and scope of the GAP that is run will depend on considerations such as demand, regulatory feasibility, the license status of the product, and necessary drug pricing structure, as well as company strategy, costs, and product supply. GAPs require careful and efficient planning and management, from set-up to closure, by either an internal coordinating project manager or by a specialist provider.

Well-run GAPs provide an ethical and regulatory-compliant pathway for access to new treatments by patients with serious conditions and unmet medical need, and enable the building of relationships with prescribers, allowing 
them to gain experience of using a drug before it becomes commercially available.

Acknowledgments Debra Ainge, Suzanne Aitken, Mark Corbett, and David De-Keyzer are employees of Clinigen Healthcare Limited. Medical writing support in researching, editing, and revising the manuscript was provided by Olivia Lunn of Bioscript Group, Macclesfield, UK and was funded by Clinigen Healthcare Limited, Burton-on-Trent, UK.

Confict of interest Some of the knowledge and information for the article has been acquired through work at Clinigen who are experts in the area of Global Access Programs.

Open Access This article is distributed under the terms of the Creative Commons Attribution Noncommercial License which permits any noncommercial use, distribution, and reproduction in any medium, provided the original author(s) and the source are credited.

\section{References}

1. Cooper E, Corbett M, DeGayner Kuker M, Fabry D, Huskinsson $\mathrm{R}$, Smith S. Improving access for patients with unmet medical needs-overview and best practice for success. A concept paper by the ISPE IP community of practice. 2014. http://www.ispe. org/concept-papers/improving-access-for-patients.pdf. Accessed 19 Nov 2014

2. Department of Health and Human Services. Food and Drug Administration. Expanded access to investigational drugs for treatment use. Federal Register. 2009;74(155):40900-45. http:// www.gpo.gov/fdsys/pkg/FR-2009-08-13/pdf/E9-19005.pdf. Accessed 19 Nov 2014.

3. Department of Health and Human Services. Food and Drug Administration. Guidance for industry. Expanded access to investigational drugs for treatment use-Qs \& As. Draft guidance. 2013. http://www.fda.gov/downloads/Drugs/GuidanceCompliance RegulatoryInformation/Guidances/UCM351261.pdf. Accessed 19 Nov 2014.

4. Hoenen T, Feldmann H. Ebolavirus in West Africa, and the use of experimental therapies or vaccines. BMC Biol. 2014;12(1):80.

5. Sou H. EU compassionate use programmes (CUPs): regulatory framework and points to consider before CUP implementation. Pharm Med. 2010;24(4):223-9.

6. Usdin S. Commentary: the equitable pathway. Biocentury. 2014;22(13):A9-11.

7. Wilking N, Jonsson B, Hogberg D. Comparator report on patient access to cancer drugs in Europe, Jan 15, 2009. http://www.lmi. no/dm_documents/comparator_report_on_patient_access_to_ cancer_drugs_in_europe_jan_15_09_wbkfi.pdf. Accessed 6 Nov 2014.

8. European Medicines Agency. Committee for Medicinal Products for Human Use (CHMP). Guideline on compassionate use of medicinal products, pursuant to article 83 of regulation (EC) No 726/2004. 2007. http://www.ema.europa.eu/docs/en_GB/document_ library/Regulatory_and_procedural_guideline/2009/10/WC50000 4075.pdf. Accessed 19 Nov 2014.

9. European Medicines Agency. Questions and answers on the compassionate use of medicines in the European Union. EMEA/ 72144/2006 (rev). 2010. http://www.ema.europa.eu/docs/en_GB/ document_library/Other/2010/01/WC500069898.pdf. Accessed 19 Nov 2014.

10. Medicines and Healthcare Products Regulatory Agency. Directive 2001/83/EC of the European Parliament and of the Council of 6 November 2001 on the Community Code Relating to Medicinal Products for Human Use. Article 5. 2001. http://webarchive. nationalarchives.gov.uk/20141205150130/http://www.mhra.gov.uk/ home/groups/es-herbal/documents/websiteresources/con009360.pdf. Accessed 19 Nov 2014.

11. Ericson M, Akers C. Named patient and other compassionate use schemes in Europe: far from a single market. Scrip Regulatory Affairs. 2012. http://www.rajpharma.com/productsector/ pharmaceuticals/Named-patient-and-other-compassionate-useschemes-in-Europe-far-from-a-single-market-329848?autnID=/ contentstore/rajpharma/codex/97bd66eb-8aed-11e1-9497ad152d0bfb07.xml. Accessed 19 Nov 2014.

12. Houÿez F, Bélorgey C, North A, Czondi E, Lipucci di Paola M. Compassionate use programmes for rare diseases: proposals for actions. Orphanet J Rare Dis. 2012;7(Suppl 2):A28.

13. Rahbari M, Rahbari NN. Compassionate use of medicinal products in Europe: current status and perspectives. Bull World Health Organ. 2011;89(3):163.

14. Urbinati D, Masetti L, Tourmi M. Early access programmes (EAPs): review of European system [poster no. PHP147]. In: ISPOR 15th Annual European Congress. Berlin; 2012.

15. Medicines and Healthcare Products Regulatory Agency. MHRA guidance note 14 on the supply of unlicensed medicinal products ('specials') updated. 2014. http://www.mhra.gov.uk/Howwer egulate/Medicines/Medicinesregulatorynews/CON413521. Accessed 19 Nov 2014.

16. Usdin S. Viral crossroads. Biocentury. 2014;22(13):A1-6.

17. Corieri C. Everyone deserves the right to try: empowering terminally ill to take control of their treatment. Goldwater Institute. Policy Report, 11 Feb 2014;266:1-30. https://goldwater-media. s3.amazonaws.com/cms_page_media/2015/1/28/Right $\% 20 \mathrm{To} \%$ 20Try.pdf. Accessed 19 Nov 2014. 